\title{
Identification and molecular analysis of 17 novel hydroxymethylbilane synthase mutations in 69 Chinese patients with acute intermittent porphyria
}

\section{Hu yuan xiang}

The first affiliated hospital of Hebei north university

\section{Li wei hao}

Hebei Medical University No2 Hospital: Second Hospital of Hebei Medical University

\section{Kang ning lin}

Hebei Medical University College of Traditional Chinese Medicine

\section{Ma li yan}

Hebei Medical University No2 Hospital: Second Hospital of Hebei Medical University

\section{Teng qing}

Hebei Medical University No2 Hospital: Second Hospital of Hebei Medical University

\section{Mo gui ling}

Guangzhou jinyu medical laboratory center

\section{Wu jia hong}

The first affiliated hospital of Hebei north university

\section{Wang xin yang}

Hebei Medical University No2 Hospital: Second Hospital of Hebei Medical University

\section{Bi ren jie}

The first affiliated hospital of Hebei north university

\section{Zhang song yun ( $\sim 2574459696 @ q q . c o m$ )}

Second Hospital of Hebei Medical University https://orcid.org/0000-0001-7038-6285

\section{Research Article}

Keywords: Acute intermittent porphyria, Hydroxymethylbilance synthase, Mutation, Molecular diagnosis, expression level

Posted Date: February 18th, 2021

DOl: https://doi.org/10.21203/rs.3.rs-183801/v1

License: (c) (1) This work is licensed under a Creative Commons Attribution 4.0 International License. Read Full License 


\section{Abstract}

BACKGROUND: Acute intermittent porphyria (AIP) is an autosomal dominant hereditary disease caused by mutations to the hydroxymethylbilane synthase (HMBS) gene in the heme biosynthesis pathway. AIP is a rare disease that is thought to display incomplete penetrance. Studies on the characteristics of $H M B S$ mutations in people from Britain, France, Russia, and Sweden have been performed.

RESULT: In this study, a total of 45 different gene mutations were found, 17 of which were novel mutations that have not been previously reported. The 45 HMBS mutations included 19 missense, 11 splicing, and 4 nonsense mutations; 9 small deletions, 1 repeat insertion, and 1 complex deletion-insertion mutation. One mutation (c.673C>T) was found in the gene sequence of 8 unrelated patients, making it the most common mutation, and another mutation (c.517C $>\mathrm{T}$ ) was found in 7 unrelated patients, making it the next most common mutation found in this study. To study the expression level of mutant $H M B S s$, Western blot and immunofluorescence staining were performed with four novel mutants (c.653G>A, c.597dupC, c.673_674del, c.1045_1046delAA), and the crystal structure changes were compared through homologous modeling to indicate the possible pathogenic mechanism.

CONCLUSIONS: In this study, the characteristics of HMBS gene mutation in Chinese were studied, which laid a foundation for further research in the future.

\section{Introduction:}

AIP occurs in all races, with most cases reported in Northern Europe, where the incidence is $5 / 100,000$. There is no difference in the mutation rate of the HMBS gene in men and women, but significant hormonal changes during the menstrual cycle make women more susceptible to the disease. AIP is often triggered by smoking, drinking, certain drugs and estrogen. The common symptoms include nausea, vomiting, abdominal pain with inconsistent signs, intestinal obstruction, high blood pressure, tachycardia, limb weakness, palsy, respiratory paralysis when respiratory muscles are involved, and even death. Mental disorders are also common, such as anxiety, depression, insomnia, and epilepsy. In addition, when the hypothalamus is involved, antidiuretic hormone syndrome may occur.

To date, the Human Gene Mutation Database (HGMD) has reported more than 500 HMBS mutations. In this study, the characteristics of mutations in Chinese AIP patients were summarized, and four novel mutations were further studied.

\section{Materials And Methods:}

\section{Genetic analysis}

Peripheral blood was collected from 69 patients with acute intermittent porphyria (obvious abdominal pain, diluted urine, neuropsychiatric symptoms, and positive urine PBG). DNA was extracted using a QIAGEN kit obtained in Germany. The gene sequences of the promoter, 15 exons and their neighboring 
introns were amplified by PCR. The total PCR system had a volume of $2.5 \mu \mathrm{l}$ and included DNA extracted from the genome at $1 \mu \mathrm{l}, 10 x$ PCR buffer at $2.5 \mu \mathrm{l}$, tap DNA polymerase at $1.25 \mathrm{U}, 2.5 \mathrm{mmol} / \mathrm{L} \mathrm{dNTPs}$, and $10 \mu \mathrm{mol} / \mathrm{L}$ upstream and downstream primers. The PCR conditions were as follows: predenaturation at $94^{\circ} \mathrm{C}$ for $5 \mathrm{~min}$, denaturation at $94^{\circ} \mathrm{C}$ for $30 \mathrm{~s}$, annealing at $60^{\circ} \mathrm{C}$ for $30 \mathrm{~s}$, and elongation at $72^{\circ} \mathrm{C}$ for $30 \mathrm{~s}$, for a total of 35 cycles. After the last cycle, the samples were elongated at $72^{\circ} \mathrm{C}$ for $5 \mathrm{~min}$ and cooled to $4^{\circ} \mathrm{C}$. The PCR amplification products were placed in a $1.5 \%$ agarose gel electrophoresis tank to ensure that the electrophoresis solution was approximately $2 \sim 3 \mathrm{~mm}$ above the gel surface. The voltage of the electrophoresis apparatus was $120 \mathrm{~V}$, and electrophoresis was performed for $30 \mathrm{~min}$. After electrophoresis, a gel imaging system was used to observe the bands and print the gel images. These determinations clearly showed visible bands of the expected size. Bidirectional gene sequencing was performed using ABI3730xI DNA.

\section{Preparation of mutants}

The synthesis of the wild-type HMBS coding sequence and the construction of the pcDNA3.1 + N-HHMBDYK recombinant plasmid were completed by Nanjing Kingsley Biotechnology Co. Loci upstream and downstream of HMBS gene were selected and digested by BamHI and Xhol enzymes. The c.673-674del, c.653G > A, c.597dupC, and c.1045-1046 mutants were prepared by site-directed mutation (Shanghai Sangon Biological Engineering Co., LTD. Shanghai China).

\section{Cell culture and transfection}

In this experiment, HeLa cells and 293T cells were provided by the Rare Disease Molecular Laboratory, Institute of Biomedical Sciences, Shanxi University. Both cell lines were cultured in high-glucose DMEM containing $10 \%$ fetal bovine serum. The cells were uniformly spread on a 12-well plate one day before transfection, and the cells were cultured to approximately $80 \%$ confluence after adhering to the wall and then transfected with mutant genes. A $1.5 \mu \mathrm{g}$ of plasmid was diluted in $100 \mu \mathrm{L}$ of pure DMEM. PEI (4.5 $\mu \mathrm{L}$ ) was added to the diluted plasmid solution and gently mixed. The plasmid mixture was allowed to stand at room temperature for $20 \mathrm{~min}$. The plasmid-PEl mixture was added to cells and cultured in an incubator with $5 \% \mathrm{CO} 2$ at $37^{\circ} \mathrm{C}$.

\section{Western blot analysis}

After $24 \mathrm{~h}$ of transfection, 293T cells were lysed, the proteins were collected, 10\% SDS-PAGE separation gel was prepared, the concentrated gel was subjected to constant pressure of $80 \mathrm{~V}$, the separation gel was subjected to constant pressure of $120 \mathrm{~V}$ and electrophoresis was performed for approximately $2 \mathrm{~h}$. The proteins were continuously transferred to the PVDF membrane with a 0.3A DC constant current for $2 \mathrm{~h}$, and the membranes wereblocked overnight with $5 \%$ skim milk at $4^{\circ} \mathrm{C}$. The primary antibodies were added, and TBST was used to wash the membrane 3 times. The secondary antibody was incubated with the membrane, which was subsequently washed with TBST 3 times. Then, the proteins on the membrane was exposed and detected. 
Twenty-four hours after transfection, the 12-well plates with HeLa cells were removed from the cell chamber, and the cells were coated onto slides, and the medium was removed. Then, the slides were fixed with $4 \%$ paraformaldehyde, covered with an anti-quenching agent and incubated for 15 min before the agent was removed, and then, the cells were rinsed with PBS. The cells were covered with $0.1 \%$ Triton X100 and incubated at room temperature for $1 \mathrm{~h}$, and then the detergent was aspirated. The cells were then incubated overnight with primary anti-FLAG antibody at $4^{\circ} \mathrm{C}$, and then the antibody solution was removed. Next, the cells were washed with PBS 3 times. The cells treated with primary antibody were then incubated with fluorescent secondary antibody and washed with PBS 3 times. The nuclei were stained and sealed, and pictures were taken using a Delta Vision imaging system.

6. Mapping the novel mutations onto the human $H M B S$ crystal structure

The amino acid sequences of wild-type HMBS and mutant-type HMBS were entered into the Swiss-Model website for homologous modeling, and the changes to the tertiary structure of the protein were analyzed and compared using PDB-Viewer.

\section{Results:}

Genomic DNA was isolated from 69 unrelated individuals with clinical symptoms consistent with AIP, and 45 different mutations were reported, 17 of which were novel mutations that have not been previously reported (see Table 1)

\section{Mutation analysis of the $H M B S$ gene}

The 45 HMBS mutations identified included 19 missense mutations, 11 splicing mutations, 4 nonsense mutations, 9 small deletions, 1 repeat insertion and 1 complex deletion-insertion mutation. Mutation c.673C > T (R225X) (in 8 patients, 8/69, 11.6\%) was identified as the most common mutation, and mutation c.517C > T (R173W) (in 7 patients, $7 / 69,10.1 \%$,) was the next most common mutation in this research. Exon 12 had 12 different mutations (12/45, 26.7\%), making it the most common exon mutant, and exon 10, which had 4 different mutations (4/45, 8.9\%), was the second most common exon mutant. Exons 7,15 and intron 14 showed 3 different $H M B S$ gene mutations $(3 / 45,6.7 \%)$, making them in the third most exon mutants (see Fig. 4).

1. 2. Expression levels and crystal structures of the 4 novel mutations

2. 2.1 The effect of HMBS mutations on the HMBS protein expression level

Western blot analysis showed that wild type- and the mutant-encoded p.G218E was expressed as a $45 \mathrm{KD}$ protein at similar levels, whereas the mutant-encoded p.N349Hfs9 was expressed at a slightly lower level than the wild type-encoded protein, and both proteins were approximately $42 \mathrm{kDa}$. Mutant-encoded p.E225Dfs7 was expressed as a $35 \mathrm{kDa}$ protein at significantly reduced levels, while p.N200Qfs8 did not appear in any band (see Fig. 1). 
Immunofluorescence staining showed that the degree to which various mutant HMBSs aggregated in the cytoplasm and nucleus was lower than that of the wild-type protein, suggesting that the expression level of wild-type HMBSs was much higher than that of the various mutants (see Fig. 2).

\subsection{Mapping the novel mutations on the human $H M B S$ crystal structure}

The crystal structure of the p.G218E mutant showed little change compared with the wild-type protein. The p.H200fs 8 mutant was prematurely terminated during the translating process at position 208 , while p.R225Dfs7 was prematurely terminated during the translation process at position 232 . The two mutants encoding these $H M B S$ s failed to encode many amino acids, which had a profound influence on the enzyme structure. The p.N349Hfs9 mutant was prematurely terminated at position 358 and showed little change in tertiary structure compared with the wild-type protein because it lacked relatively few amino acids (see Fig. 3).

Therefore, it was speculated that p.G218E and p.N349Hfs9 has little influence on the crystal structure of the enzymes, while p.H200fs8 and p.R225Dfs7 showed greater influence on the structure of the enzymes.

\section{Discussion:}

Porphyria is a metabolic disease caused by abnormal enzyme activity due to gene mutations during heme synthesis. Porphyria can be classified into acute porphyria and cutaneous porphyria according to the clinical manifestations, and AIP is the most common type of acute porphyria. AIP is an autosomal dominant disorder due to the half-normal activity of $H M B S$ and is characterized by acute neurovisceral attacks precipitated by factors that induce heme biosynthesis.

The HMBS gene is located on chromosome 11 and consists of 15 exons and 14 introns. The whole HMBS protein serves as an enzyme with cofactors. The enzyme is composed of 361 amino acids, including 3 domains, in which the $\mathrm{C} 261$ residue is the key residue and is in domain 3; it covalently binds to cofactors. The cofactors consist of $\mathrm{C} 1$ and $\mathrm{C} 2$ rings, and the $\mathrm{C} 1$ ring binds to $\mathrm{C} 261$ in domain 3. HMBS is a monomeric enzyme that catalyzes the stepwise head-to-tail condensation of four porphobilinogen (PBG) molecules to form linear tetrapyrrole 1-hydroxymethylbilane (HMB). This process depends on the cofactors and the movement of the hinge between domains 1 and 2, including amino acids S96, H120, and L238 and fragments at amino acid positions 116-118, $106-11,147-156$, and 206-221[1].

This study revealed that $\mathrm{c} .673 \mathrm{C}>\mathrm{T}$ was the most common mutation and that the $\mathrm{c} .517 \mathrm{C}>\mathrm{T}$ mutation was the next most common mutation. From the location of the mutant genes, exon 12 was determined to be the most common exon mutant, and exon 10 was the second most common exon mutant, and intron 14 along with exons 7 and 15 were the third most common mutants. Reviewing the relevant literature, we found that the less common mutation, $c .517 \mathrm{C}>\mathrm{T}$, in Chinese patients was the most common mutation in Russian and Canadian patients. HMBS mutations in samples from Sweden and the UK frequently occurred in exon 12, followed by exon 10, which was consistent with our research. The difference between the current and previous studies was that exon 7 ranked third only among samples from Sweden 
and the UK, while intron 14, along with exons 7 and 15 , were the third most common mutants in our research[2-6].

c.673C > T (p.R225X) was the most common mutation in the Chinese AIP patients. It is a nonsense mutation occurring in exon 11 and results in the termination of amino acid translation at position 225 . This mutation missed the 136 amino acid in the C-terminus, including the $\mathrm{C} 261$ residue in domain 3 , which directly affects the initiation of HMB formation.

c.517C > T (R173W) was a less common mutation in the Chinese AIP patients, occurring in exon 10 in the $H M B S$ gene. R173 is located in the active site of $H M B S$ and plays an important role in PBG entry into the active site. The possible pathogenesis of other known mutations is shown in Table 2.

In this in-depth study conducted on 4 novel mutations, homologous modeling on the Swiss-Model website was carried out with these novel mutants, and changes to the protein crystal structure were analyzed using PB-Viewer software. The c.653G > A (p.G218E) mutation led to the substitution of glycine at 218 with a glutamate. As glycine at 218 plays an important role in the hinge movement of $H M B S$, it was speculated that the mutation may affect the opening and closing of the active center. Although the mutation does not cause a significant change in the crystal structure of the enzyme (Fig. 3), it affects enzyme activity. c.597dupC (p.H200fs8) led to premature termination at position 208 during the translation process, leading to the absence of 153 amino acids; c.673_674del (p.R225Dfs7) led to the premature termination at position 232 during the translation process, and 129 amino acids were thus missing. These two mutants encoded translated truncated proteins that lacked many amino acids and influenced the enzyme structures (Fig. 3). In addition, these two mutations led to the absence of important amino acids, such as C238 and C261, affecting substrate binding and hinge movement. c.1045_1046delAA (p.N349Hfs9) changed the amino acid coding sequence at position 349 and led to termination at position 358. This mutation led to the loss of 3 amino acids in the $\mathrm{C}$-terminus and showed a slight influence on the crystal structure of $H M B S$ (Fig. 3). In addition, because the glutamine at position 356 extended the tetrapyrrole rings, the arginine substitution for glutamine may affect the enzyme activity.

The encoding region of $H M B S$ contains $1035 \mathrm{bp}$, and the target band of the final wild-type was expected to $39.18 \mathrm{kDa}$, including the FLAG tag. However, the results of the Western blot in this research showed that the molecular weight of the wild-type $H M B S$ was approximately $45 \mathrm{kDa}$, and the mutant $H M B S$ s were also approximately $6 \mathrm{kDa}$ higher than predicted. In fact, SDS-PAGE is a technique for separating proteins according to molecular weight. In general, smaller proteins move faster through the gel. However, migration is also influenced by other factors, such as phosphorylation and glycosylation, which lead to true bands that differ from the predicted bands. In this study, the Western blot results showed that the molecular weight of the protein expressed by the wild-type and missense mutation c.653G > A (G218E) was approximately $45 \mathrm{kDa}$, while the molecular weight of the protein expressed by the frame-shifted mutation c.1045_1046delAA (N349Hfs9) was slightly lower than that of the wild-type, at approximately $42 \mathrm{kDa}$. The molecular weight of the protein expressed by c.673_674del (p.E225Dfs7) was approximately 
$35 \mathrm{kDa}$. c.597dupC (N200Qfs8) was not visible because the few amino acids encoded were not stable in the cell and degraded after translation. This may also be the reason why the other two truncated proteins encoded by genes with these 4 novel mutations constitute a low percentage of the cell content.

\section{Conclusions}

As of February 2020, a total of 517 HMBS gene mutations were reported, and 2 novel mutations were separately reported by Yang $J$ in April 2020 and by Yang $Y$ in July 2020 [7, 8]. In addition, María-José Morán-Jiménez investigated the molecular defects in 55 unrelated Spanish patients with AIP, identifying 6 novel mutations[9]. With the addition of 17 new mutations from this study, the number of $H M B S$ mutations has increased to 542. This study simply analyzed the reasons for the decreased expression levels and stability of $H M B S$ mutants compared with wild-type HMBS. In addition, the mechanism of the decrease in enzyme activity caused by the known mutations was also analyzed. The deficiency of this study was that Western blotting, immunofluorescence staining and spatial structure prediction were not performed for all the novel mutations, and enzyme activity was not determined. In future studies, we will conduct in-depth studies on the expression levels, stability, changes in spatial structure and enzyme activity of the HMBS mutants, and analyze the mechanism of the decrease in enzyme activity, which will contribute to improvements in the activity of $H M B S$ for use in potential treatments.

\section{Declarations}

\section{Acknowledgments}

We thank all the patients for their participation, the physicians for performing the investigations and the laboratory staff for excellent technical assistance. We also thank the Chinese AIP patients who actively supported the research of our group.

\section{Authors' contributions}

xiang Huyuan,hao Liwei designed the experiment and wrote the manuscript.lin Kangning helped with the Genetic analysis.yan Mali and qing Teng ran the Preparation of mutants. ling Mogui helped with Cell culture and transfection. hong Wujia ${ }^{1}$, yang Wangxin peformed the Western blot analysis and Immunofluorescence staining. jie Biren Mapped the novel mutations onto the human HMBS crystal structure. yun Zhangsong obtained funding, led the research and worte the manuscript.All authors read and approved the final manuscript.

\section{Funding}

This work was supported by the foundation named Exploration of Genotype-phenotype Relationship for Acute Intermittent Porphyria at The Second Hospital of Hebei Medical University.

\section{Availability of data and materials}


The datasets used and analysed during the current study are available from the corresponding author on reasonable request. All other data generated or analysed during this study are included in this published article and its supplementary information files.

\section{Ethical approval}

The subjects in this study understood the purpose and significance of this research and signed informed consent documents. In addition, all the procedures of this study were reviewed by the Second Hospital of Hebei Medical University. Animal were not involved in this research.

\section{Consent for publication}

All authors have read and agreed to the published version of the manuscript.

\section{Competing interests}

There were no competing interests for any of the authors or patients.

\section{Author details}

${ }^{1}$ Department of Geriatrics, The First Affiliated Hospital of Hebei North University; ${ }^{2}$ Department of Special Examination, The Second Hospital of Hebei Medical University; ${ }^{3}$ Department of Endocrinology, Hebei Hospital of Traditional Chinese Medicine; ${ }^{4}$ Department of Rheumatology, The Second Hospital of Hebei Medical University; ${ }^{5}$ Department of Endocrinology, The Second Hospital of Hebei Medical University; ${ }^{6}$ Guangzhou Jinyu Medical Laboratory Center Co., Ltd. ${ }^{7}$ Department of Gastrointestinal Oncology, The First Affiliated Hospital of Hebei North University;Correspondence should be addressed to Songyun Zhang (2574459696@qq.com).

\section{Abbreviations}

AIP: Acute intermittent porphyriary;HMBS Hydroxymethylbilane synthase;PBG porphobilinogen;PBGD Porphobilinogen deaminase.

\section{References}

[1] Bung,N., Roy,A., Chen,B., Das,D., Pradhan,M., Yasuda,M., New,M.I., Desnick,R.J., and Bulusu,G. (2018) Human hydroxymethylbilane synthase: Molecular dynamics of the py rrole chain elongation identifies step-specific residues that cause AIP. Proc. Natl. Acad. Sci.,USA.,115,E4071-E4080.

[2] Floderus,Y., Shoolingin-Jordan,P.M., Harper,P. (2002) Acute intermittent porphyria in Sweden. Molecular, functional and clinical consequences of some new mutations found in the porphobilinogen deaminase gene. Clin. Genet., 62, 288-297. 
[3] Whatley,S.D., Woolf,J.R., Elder,G.H. (1999) Comparison of complementary and genomic DNA sequencing for the detection of mutations in the HMBS gene in British patients with acute intermittent porphyria: identification of 25 novel mutations. Hum,Genet.,104, 505-510.

[4] Greene-Davis,S.T., Neuman, P.E., Mann,O.E., Moss,M.A., Schreiber,W.E., Welch,J.P., Langlley,G.R., Sangalang,V.E., Dempsey,G.I., and Nassar,B.A. (1997) Detection of a R173W mutation in the porphobilinogen deaminase gene in the Nova Scotian "foreign Protestant" population with acute intermittent porphyria: a founder effect. Clin,Biochem.,30,607-612.

[5] Surin,V.L., Luchinina,lu.A., Selivanova,D.S., Pustovoĭt,la.S., Karpova,I.S., Pivnik ,A.V., Luk'ianenko, A.V., Kravchenko,S.K.(2010) Molecular genetic study of acute intermittent porphyria in Russia: mutation analysis and functional polymorphism search in porphobilinogen deaminase gene. Genetika, 46,540-552.

[6] Lee,J.S., Lundin,G., Lannfelt,L., Forseli,L., Picat,C., Grandchamp,B.,and Anvret ,M.(1991) Genetic heterogeneity of the porphobilinogen deaminase gene in Swedish families with acute intermittent porphyria. Hum,Genet,87,484-488.

[7] Yang,J., Han,F., Chen,Q., Zhu,T., Zhao,Y., Yu,X., Zhu,H., Cao,J., Li,X.(2020) Reversible splenial lesion syndrome (RESLES) due to acute intermittent porphyria with a novel mutation in the hydroxymethylbilane synthase gene. Orphanet,J,Rare,Dis,15,98.

[8] Yang,Y., Xiyun,C.,Huijuan,W., Hua,P., Wenjing,S., Bin,H., and Zhengang,Y.(2020) A novel heterozygous mutation in the HMBS gene in a patient with acute intermittent porphyria and posterior reversible encephalopathy syndrome. Mol,Med,Rep,2020,22,516-524.

[9] Morán-Jiménez,M.J., Borrero-Corte,M.J., Jara-Rubio,F., García-Pastor,I., Díaz-Díaz,S.(2020) Molecular Analysis of 55 Spanish Patients with Acute Intermittent Porphyria.Genes (Basel),11,924.

[10] Llewellyn,D.H., Whatley,S., Elder,G.H..(1993) Acute intermittent porphyria caused by an arginine to histidine substitution (R26H) in the cofactor-binding cleft of porphobilinogen deaminase. Hum,Mol,Genet,1993,1315-1316.

[11] Lundin,G., Lee,J.S., Thunell,S., Anvret,M.(1997) Genetic investigation of the porphobilinogen deaminase gene in Swedish acute intermittent porphyria families. Hum,Genet,100,63-66.

[12] Solis,C., Lopez-Echaniz,I., Sefarty-Graneda,D., Astrin,K.H., Desnick,R.J.(1999) Identification and expression of mutations in the hydroxymethylbilane synthase gene causing acute intermittent porphyria (AIP). Mol,Med,5,664-671.

[13] Shoolingin-Jordan,P.M., Al-Dbass,A., McNeill,L.A., Sarwar,M., Butler,D.(2003) Human porphobilinogen deaminase mutations in the investigation of the mechanism of dipyrromethane cofactor assembly and tetrapyrrole formation. Biochem,Soc,Trans,31,731-735. 
[14] Ulbrichova,D., Hrdinka,M., Saudek,V., Martasek,P.(2009) Acute intermittent porphyria-impact of mutations found in the hydroxymethylbilane synthase gene on biochemical and enzymatic protein properties. FEBS,J,276,2106-2115.

[15] Gregor,A., Schneider-Yin,X., Szlendak,U., Wettstein,A., Lipniacka,A., Rüfenacht,U.B., Minder,E.I. (2002) Molecular study of the hydroxymethylbilane synthase gene (HMBS) among Polish patients with acute intermittent porphyria. Hum,Mutat,19,310.

[16] Kauppinen,R., von,und, zu, Fraunberg,M.(2002) Molecular and biochemical studies of acute intermittent porphyria in 196 patients and their families. Clin,Chem,48,1891-1900.

[17] Chen,B., Solis-Villa,C., Hakenberg,J., Qiao,W., Srinivasan,R.R., Yasuda,M., Balwani, M., Doheny,D. (2016) Acute Intermittent Porphyria: Predicted Pathogenicity of HMBS Variants Indicates Extremely Low Penetrance of the Autosomal Dominant Disease. Hum,Mutat,2016,37,1215-1222.

[18] Lenglet,H., Schmitt,C., Grange T, Manceau,H., Karboul,N., Bouchet-

Crivat,F., Robreau,A.M., Nicolas,G. (2018) From a dominant to an oligogenic model of inheritance with environmental modifiers in acute intermittent porphyria. Hum,Mol,Genet,27, 1164-1173.

[19] Brewer,C.T., Kodali,K., Wu,J., Shaw,T.I., Peng,J., Chen,T.(2009) Structural insight into acute intermittent porphyria. $F A S E B, J, 23,396-404$.

[20] Chen,B., Solis-

Villa,C., Erwin,A.L., Balwani,M., Nazarenko,I., Phillips,J.D., Desnick,R.J., Yasuda,M.(2019) Identification and characterization of 40 novel hydroxymethylbilane synthase mutations that cause acute intermittent porphyria. J Inherit Metab Dis,42,186-194.

[21] Liu,G., Li,X., Shu,H., Hu,Y.L., Anderson,G., Qian,J., Nie,G..(2011) Identification of two novel PBGD mutations in acute intermittent porphyria patients accompanying anemia in mainland China. Blood Cells Mol Dis, 47,138-139.

[22] Mgone,C.S., Lanyon,W.G., Moore,M.R., Louie,G.V., Connor,J.M.(1994) Identification of five novel mutations in the porphobilinogen deaminase gene. Hum Mol Genet,3,809-811.

[23] Petersen,N.E., Nissen,H., Hansen,T.S., Rasmussen,K., Brock,A., Horder,M.(1996) R325X mutation in exon 15 of the hydroxymethylbilane synthase gene identified in two Danish families with acute intermittent porphyria. Clin, Chem, 42,106-107.

[24] Daimon,M., Yamatani,K., Igarashi,M., Fykase,N., Sasaki,H.(1993) Acute intermittent porphyria caused by a $\mathrm{G}$ to $\mathrm{C}$ mutation in exon 12 of the porphobilinogen deaminase gene that results in exon skipping. Hum,Gene, 92,549-553.

[25] Mgone,C.S., Lanyon,W.G., Moore,M.R., Louie,G.V., Connor,J.M.(1993) Detection of a high mutation frequency in exon 12 of the porphobilinogen deaminase gene in patients with acute intermittent 
porphyria. Hum,Genet,92, 619-622.

[26] Chen,C,H., Astrin,K.H., Lee,G., Anderson,K.E., Desnick,R.J.(1994) Acute intermittent porphyria: identification and expression of exonic mutations in the hydroxymethylbilane synthase gene. An initiation codon missense mutation in the housekeeping transcript causes "variant acute intermittent porphyria" with normal expression of the erythroid-specific enzyme. J,Clin,Inves, 94, 1927-1937.

\section{Tables}

Due to technical limitations, the tables are available as a download in the supplementary files section.

\section{Figures}

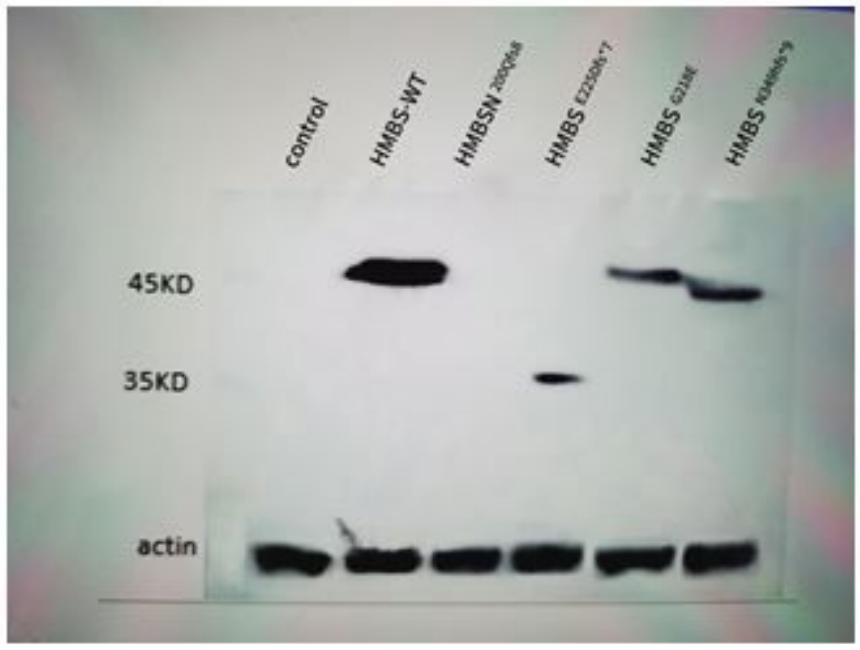

\section{Figure 1}

Comparison of the proteins expressed in wild-type and mutant cells 


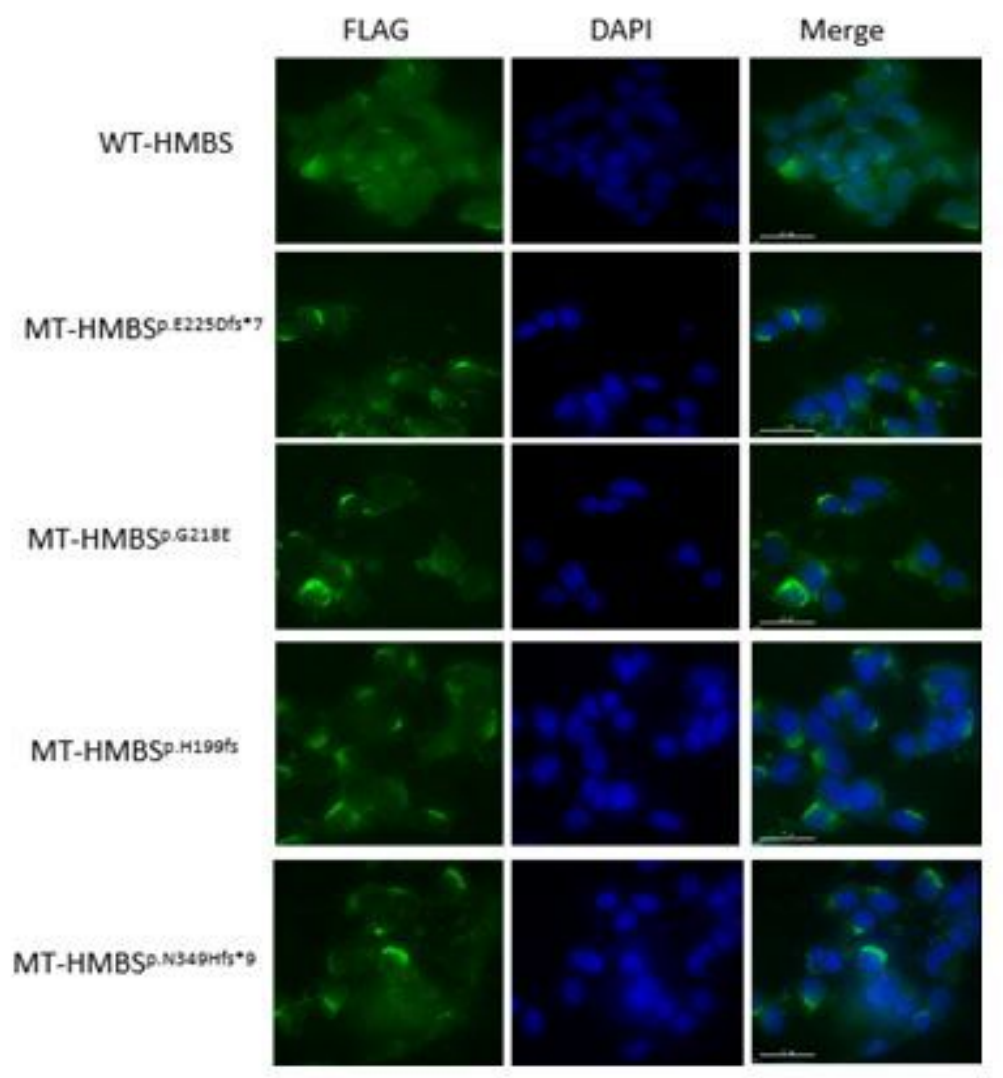

\section{Figure 2}

Immunofluorescence staining of HeLa cells transfected with wild-type and mutant plasmids
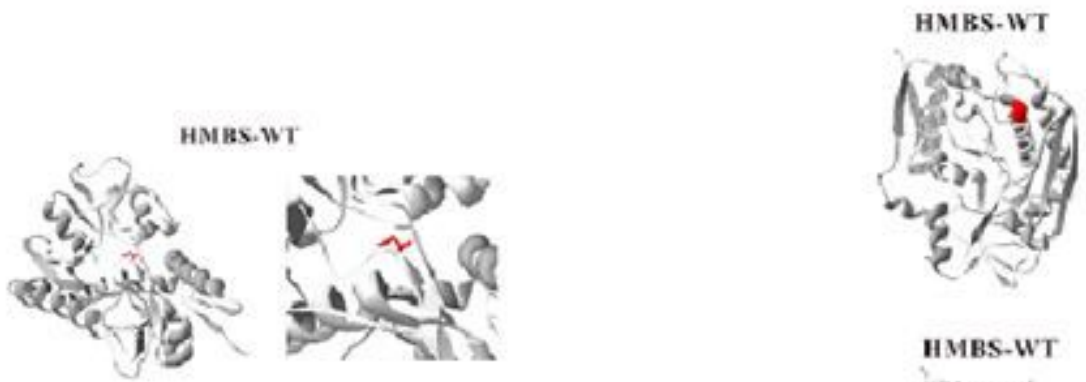

HYBS-E225Dfs 27
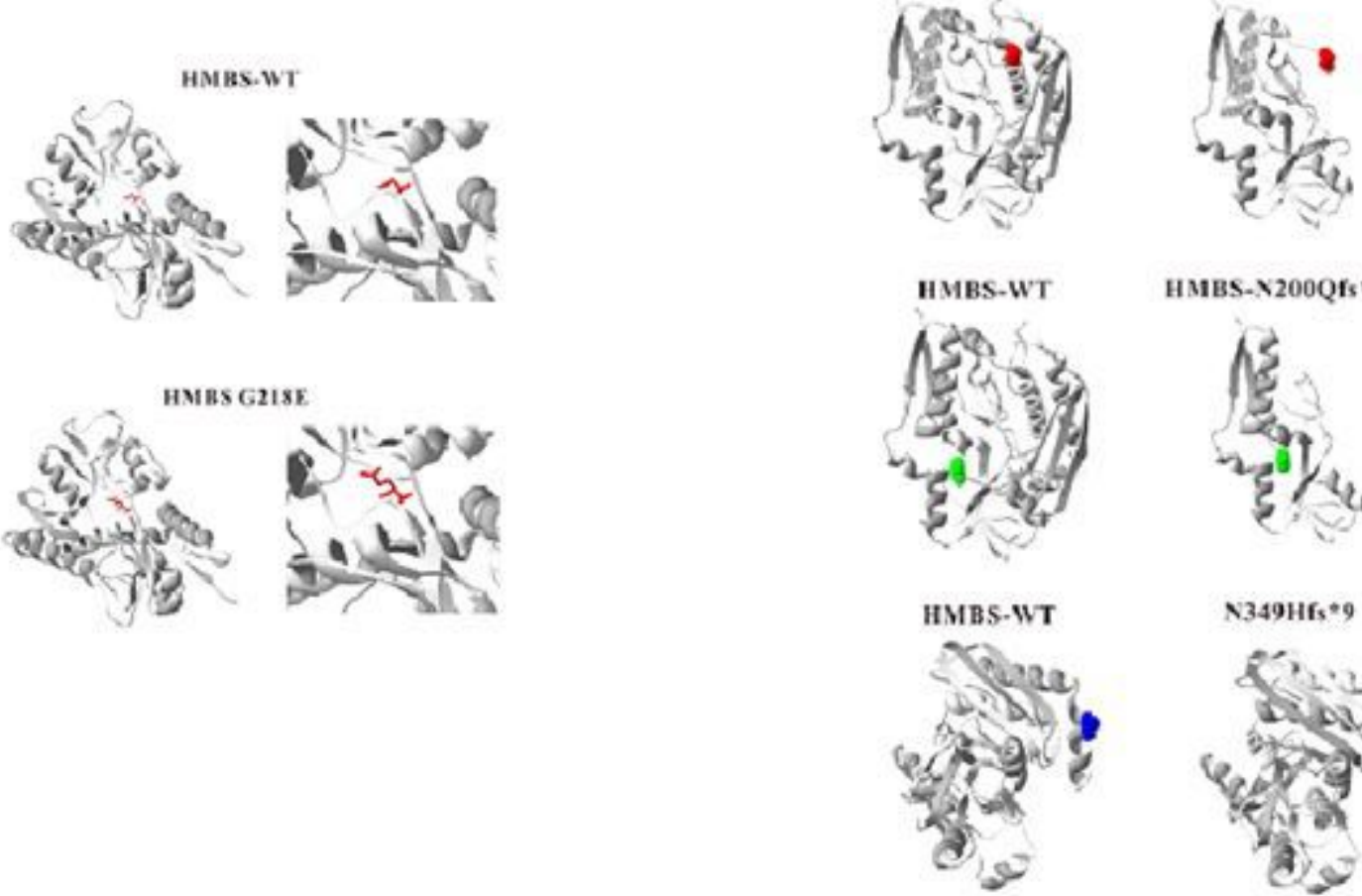

HMBS- $\times 200 Q f s * 8$

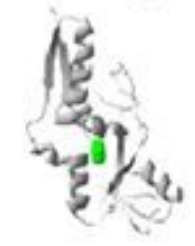

N349Hfs*9

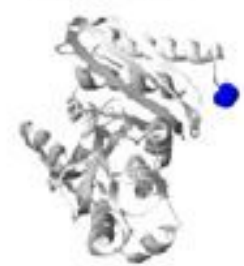




\section{Figure 3}

New mutations c.653G>A, c.673_674del, c.597dupC, and c.1045_1046delAA expressed in the tertiary structure of HMBS

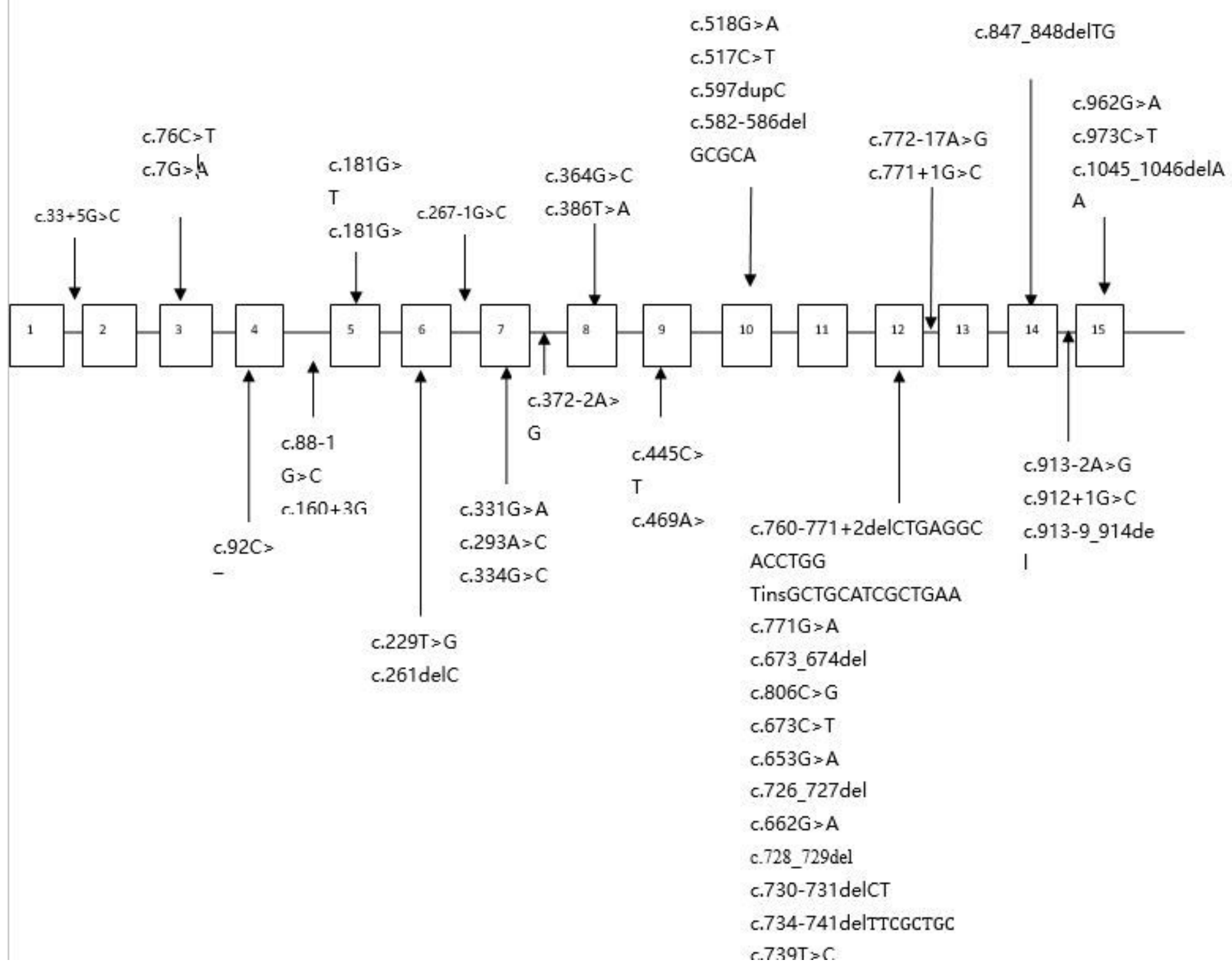

Figure 4

Separate exons and introns in the 45 HMBS gene mutations in this study

\section{Supplementary Files}

This is a list of supplementary files associated with this preprint. Click to download.

- Table.pdf 